\title{
Analysis of Hazardous-Chemicals-Transportation Based on Interpretative Structural Modeling
}

\author{
X.Z. Liu \& D.L Qian \\ A.A. Beijing Jiaotong University, Beijing, China
}

ABSTRACT: 235 transportation accidents occurred in the year of 2015 involving dangerous chemicals were analyzed from the time of the accident cause, occurrence, location of accident. Identify risk factors in the transportation process. It is classified for risk factors, attributed to seven major categories. To tease out the relationship of the risk factors in transport, and Interpretative Structural Modeling (ISM) for risk factors is built. Based on mutual relationships of these factors and different levels, analyze the existing main problems are analyzed in transportation of dangerous goods.

KEYWORD: Hghway Transportation; Risk factors; ISM; Hazardous materials; Accident

\section{INTRODUCTION}

The definition of dangerous chemicals in "Catalog of Hazardous chemicals " is that toxic chemicals or other chemicals that are toxic, corrosive, explosive, flammable and etc. The transportation of chemicals is not only increasing the number of it, but also the risk of it is more complex than before. According to relevant statistics, China's transport of dangerous chemicals involved in more than 95\% of the total number of accounts for a large off-site transport. The number of dangerous chemicals transportation by road is about 200 million tons each year. As most of the dangerous goods have a strong explosive nature, safe operation of the storage and transportation work is very important. The threat of dangerous goods in transit can't be ignored. For example, March 1, 2014, two tankers carrying methanol in Jinji highway rear-end caused blasting accident. This accident caused 40 people were killed and 12 people were injured (Carlos S, 2007).

\section{RISK FACTORS ANALYSIS}

This paper statistics 235 transportation accidents occurred in the year of 2015 involving dangerous chemicals. In this section, the main reason for the accident is divided into seven categories (Figure 1): The driver factors, vehicle or equipment factors, the collision by others, weather conditions, road conditions, management factors and the state of the goods. On the basis, we put the specific reasons for each category in the statistical classification, forming the cause of the accident statistics (Table 1).

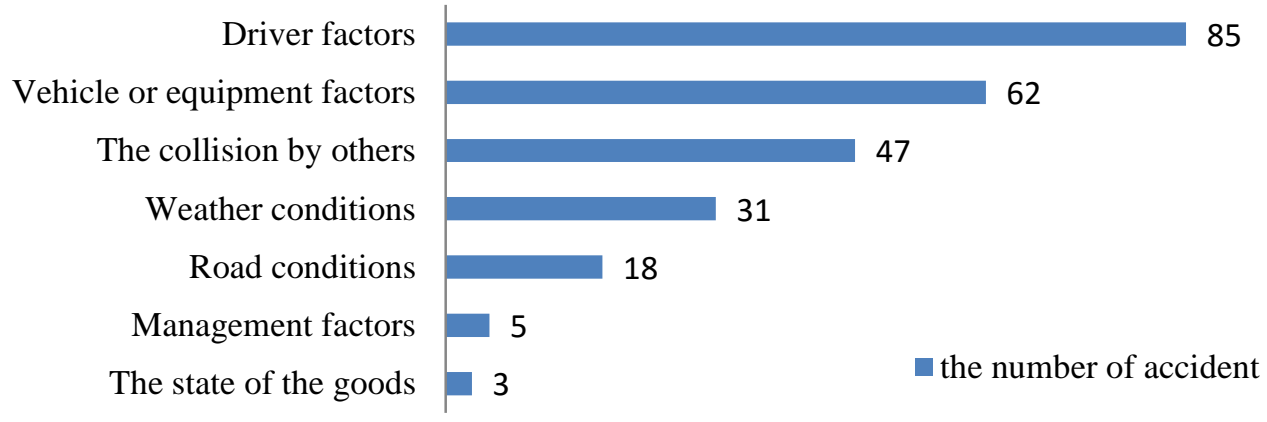

Figure1. Main factors in the dangerous chemical transportation

Note: Total number of the factors is greater than the total number of accidents, because one accident may be caused by one or more reasons.

From figure1, we can see that the reason in process of transportation caused by driver's misconduct which accounts for $33.9 \%$ of the total is the first critical factor. What's more, it is often associated with more casualties and property losses. Especially when driving in traffic better roads (highways, national highways, etc.), the vehicle speed is relatively fast and the larger volume of the 
vehicle, the driver's misconduct may have their own and other vehicles greater impact. Therefore, standardizing driver's safe driving behavior is very important. The proportion of accidents caused by vehicle or equipment failure is $24.7 \%$. Usually this type of accident will appear varying degrees of chemical spills, which is vital that can't be ignored in the transport process. The weather, road, cargo status and other factors belong to objective factors. When companies accept the transport task, we should take full account of these uncontrollable factors to choose the line to avoid bad weather and the complex terrain.

Table 1 Main factor in the dangerous chemical transportation

\begin{tabular}{|c|c|c|c|c|c|}
\hline Accident type & Frequency & Rate & Specific reason & Frequency & Rate \\
\hline \multirow{4}{*}{ The driver factors } & \multirow{4}{*}{85} & \multirow{4}{*}{$33.9 \%$} & Improper avoid & 35 & $41.2 \%$ \\
\hline & & & Improper operation & 26 & $30.5 \%$ \\
\hline & & & Overspeed & 14 & $16.5 \%$ \\
\hline & & & Bad condition of driving & 10 & $11.8 \%$ \\
\hline \multirow{6}{*}{ vehicle or equipment factors } & \multirow{6}{*}{62} & \multirow{6}{*}{$24.7 \%$} & Tire fault & 19 & $30.6 \%$ \\
\hline & & & Brake fault & 12 & $19.3 \%$ \\
\hline & & & Tank body breakage & 10 & $16.2 \%$ \\
\hline & & & fire & 7 & $11.3 \%$ \\
\hline & & & Valve fault & 6 & $9.7 \%$ \\
\hline & & & other ${ }^{*}$ & 8 & $12.9 \%$ \\
\hline \multirow{3}{*}{ weather conditions } & \multirow{3}{*}{31} & \multirow{3}{*}{$12.4 \%$} & Rain & 14 & $45.2 \%$ \\
\hline & & & Fog & 10 & $32.2 \%$ \\
\hline & & & Snow & 7 & $22.6 \%$ \\
\hline \multirow{5}{*}{ road conditions } & \multirow{5}{*}{18} & \multirow{5}{*}{$7.1 \%$} & Sharp turn & 8 & $44.4 \%$ \\
\hline & & & Skidded & 7 & $38.9 \%$ \\
\hline & & & Bump & 1 & $5.6 \%$ \\
\hline & & & Long downhill & 1 & $5.6 \%$ \\
\hline & & & Narrow road & 1 & $5.6 \%$ \\
\hline the collision by other cars ${ }^{* *}$ & 47 & $18.7 \%$ & 1 & 1 & 1 \\
\hline management factors & 5 & $2.0 \%$ & 1 & 1 & 1 \\
\hline the state of the goods & 3 & $1.2 \%$ & I & I & l \\
\hline
\end{tabular}

\section{RISK FACTORS ANALYSIS}

Interpretative Structural Modeling is a structured model which is the most commonly used method. The system is a method for the analysis of complex social and economic issues developed by Professor J - Warfield American in 1973.

In this section, we use ISM to build a multi-step structure to card the relationship of risk factors during transport of hazardous chemicals. We focus on the need for transportation companies. Help policy makers who should focus on the key point to find out direct and indirect risk factors. Then it will improve the decision-making efficiency (WU Zong-zhi et al, 2011) (YANG Jun-min et al, 2011) and reduce the number of accident.

\subsection{Analysis the relationship of the risk factors}

In this section, we select major risk factors during transportation of hazardous chemicals, using of the preliminary findings of the accident statistical analysis. Through discussing by expert consultation, questionnaire method and literature reference, relying on the "road safety risk prevention and control of key technology of high-risk passenger transportation" project, we analyze the relationship between these factors in depth. Finally, we confirm the key issues: the accident of hazardous chemicals during transport $\left(D_{1}\right)$ and the interrelationship between 14 existing risk factors $\left(D_{i}, i=2,3, \ldots, 15\right)$. Specific risk factors are described in Table 2.

Table 2 The risk factors of hazardous chemicals during transportation

Key issues: the accident of hazardous chemicals during transport $\left(\mathrm{D}_{1}\right)$

Risk factors

\begin{tabular}{|c|c|c|}
\hline $\begin{array}{l}\text { Risk } \\
\text { factor }\end{array}$ & Specific describe & Type \\
\hline $\mathrm{D}_{2}$ & Improper avoid & \multirow{4}{*}{ driver } \\
\hline $\mathrm{D}_{3}$ & Improper operation & \\
\hline $\mathrm{D}_{4}$ & Over speed & \\
\hline $\mathrm{D}_{5}$ & Bad condition of driving & \\
\hline $\mathrm{D}_{6}$ & Tank body breakage & \multirow{4}{*}{ Vehicle or equipment } \\
\hline $\mathrm{D}_{7}$ & Tire fault & \\
\hline $\mathrm{D}_{8}$ & Brake fault & \\
\hline $\mathrm{D}_{9}$ & Fire & \\
\hline $\mathrm{D}_{10}$ & Collide by other cars & Collide by other cars \\
\hline $\mathrm{D}_{11}$ & Rain & \multirow{3}{*}{ Weather } \\
\hline $\mathrm{D}_{12}$ & Snow & \\
\hline $\mathrm{D}_{13}$ & Fog & \\
\hline $\mathrm{D}_{14}$ & Road-quality problems & Road \\
\hline $\mathrm{D}_{15}$ & management failure & Management \\
\hline
\end{tabular}

\subsection{Establish adjacency matrix and reachability}


matrix

Adjacency matrix A is used to indicate whether there are problems in a direct relationship between the various elements of the system. Element aij in A can be defined as:

$\mathrm{a}_{\mathrm{ij}}=\left\{\begin{array}{cr}1 & D_{i} \text { can directly reach } \mathrm{D}_{j} \\ 0 & D_{i} \text { can't directly reach } \mathrm{D}_{j}\end{array}\right.$

The adjacency matrix A represented the relationship between the various risk factors for the transport of dangerous goods is as follow:

$\begin{array}{lllllllllll}D_{1} & D_{2} & D_{3} D_{4} & D_{5} & D_{6} D_{7} & D_{8} & D_{9} D_{10} & D_{11} D_{12} D_{13} D_{14} D_{15}\end{array}$

\begin{tabular}{|c|c|c|c|c|c|c|c|c|c|c|c|c|c|}
\hline$D_{1}$ & 0 & 0 & 0 & 0 & 0 & 0 & 0 & 0 & 0 & & 0 & 0 & 0 \\
\hline$D_{2}$ & 10 & 0 & 0 & 0 & 0 & 0 & 0 & 0 & 0 & 0 & 0 & 0 & 0 \\
\hline$D_{3}$ & 10 & 0 & 0 & 0 & 0 & 0 & 0 & 0 & 0 & 0 & 0 & 0 & 0 \\
\hline$D_{4}$ & 10 & 0 & 0 & 0 & 0 & 0 & 0 & 0 & 0 & 0 & 0 & 0 & 0 \\
\hline$D_{5}$ & $\begin{array}{ll}1 & 1\end{array}$ & 1 & 0 & 0 & 0 & 0 & 0 & 0 & 0 & 0 & 0 & 0 & 0 \\
\hline$D_{6}$ & 10 & 0 & 0 & 0 & 0 & 0 & 0 & 0 & 0 & 0 & 0 & 0 & 0 \\
\hline$D_{7}$ & $\begin{array}{ll}1 & 1\end{array}$ & 0 & 0 & 0 & 0 & 0 & 0 & 1 & 0 & 0 & 0 & 0 & 0 \\
\hline$D_{8}$ & $\begin{array}{ll}1 & 0\end{array}$ & 0 & 0 & 0 & 0 & 0 & 0 & 0 & 0 & 0 & 0 & 0 & 0 \\
\hline$D_{9}$ & 10 & 0 & 0 & 0 & 0 & 0 & 0 & 0 & 0 & 0 & 0 & 0 & 0 \\
\hline$D_{10}$ & 10 & 0 & 0 & 0 & 1 & 0 & 0 & 0 & 0 & 0 & 0 & 0 & 0 \\
\hline 11 & $\begin{array}{ll}0 & 1\end{array}$ & 1 & 0 & 0 & 0 & 0 & 0 & 0 & 0 & 0 & 0 & 0 & 1 \\
\hline 12 & $\begin{array}{ll}0 & 1\end{array}$ & 1 & 0 & 0 & 0 & 0 & 0 & 0 & 0 & 0 & 0 & 0 & 1 \\
\hline 13 & $\begin{array}{ll}0 & 0\end{array}$ & 1 & 0 & 0 & 0 & 0 & 0 & 0 & 0 & 0 & 0 & 0 & 1 \\
\hline 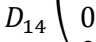 & $\begin{array}{ll}0 & 1\end{array}$ & 1 & 0 & 0 & 0 & 0 & 0 & 0 & 0 & 0 & 1 & 0 & 0 \\
\hline & 1 & 0 & 0 & 1 & 1 & 1 & 1 & 0 & 0 & & 0 & 0 & 0 \\
\hline
\end{tabular}

Reachability matrix $\mathrm{R}$ represents a direct or indirect relationship existing between any two different elements in the structure. It refers to the form of a matrix to describe the degree of each node in connection diagram can be reached. Reachability matrix has the most significant feature: the elapse. According to the following equation using the properties can be calculated reachability matrix R. Order $\mathrm{Ai}=(\mathrm{A}+\mathrm{I}) \mathrm{i}, 1 \leq \mathrm{i} \leq \mathrm{n}-1$, Using Boolean arithmetic rule $(0+0=0,0+1=1,1+0=1,1+1$ $=1,0 \times 0=0,0 \times 1=0,1 \times 0=0,1 \times 1=1)$

$\mathrm{A}_{1} \neq \mathrm{A}_{2} \neq \ldots \neq \mathrm{A}_{\mathrm{r}-1}=\mathrm{A}_{\mathrm{r}}, \mathrm{r} \leq \mathrm{n}-1$

In the formula: $\mathrm{n}$ is the matrix order,

$A_{r-1}=(A+I)_{r-1}=R$

By using MATLAB calculation, outputs to R:

$\begin{array}{llllllllllllll}D_{1} & D_{2} & D_{3} & D_{4} & D_{5} & D_{6} D_{7} & D_{8} & D_{9} D_{10} & D_{11} D_{12} D_{13} D_{14} D_{15}\end{array}$

\begin{tabular}{|c|c|c|c|c|c|c|c|c|c|c|c|c|c|}
\hline$D_{1}$ & 1 & 0 & 0 & 0 & 0 & 0 & 0 & 0 & 0 & 0 & 0 & & \\
\hline$D_{2}$ & $\begin{array}{ll}1 & 0\end{array}$ & 0 & 0 & 0 & 0 & 0 & 0 & 0 & 0 & 0 & 0 & 0 & \\
\hline$D_{3}$ & 10 & 1 & 0 & 0 & 0 & 0 & 0 & 0 & 0 & 0 & 0 & 0 & 0 \\
\hline$D_{4}$ & 10 & 0 & 1 & 0 & 0 & 0 & 0 & 0 & 0 & 0 & 0 & 0 & 0 \\
\hline$D_{5}$ & 1 & 1 & 0 & 1 & 0 & 0 & 0 & 0 & 0 & 0 & 0 & 0 & 0 \\
\hline$D_{6}$ & 1 & 0 & 0 & 0 & 1 & 0 & 0 & 0 & 0 & 0 & 0 & 0 & 0 \\
\hline$D_{7}$ & 1 & 0 & 0 & 0 & 0 & 1 & 0 & 0 & 0 & 0 & 0 & 0 & 0 \\
\hline$D_{8}$ & 1 & 0 & 0 & 0 & 0 & 0 & 1 & 0 & 0 & 0 & 0 & 0 & 0 \\
\hline$D_{9}$ & 1 & 0 & 0 & 0 & 0 & 1 & 0 & 1 & 0 & 0 & 0 & 0 & 0 \\
\hline$D_{10}$ & 10 & 0 & 0 & 0 & 1 & 0 & 0 & 0 & 1 & 0 & 0 & 0 & 0 \\
\hline$D_{11}$ & 11 & 1 & 0 & 0 & 0 & 0 & 0 & 0 & 0 & 1 & 0 & 0 & 1 \\
\hline$D_{12}$ & 11 & 1 & 0 & 0 & 0 & 0 & 0 & 0 & 0 & 0 & 1 & 0 & 1 \\
\hline 13 & 11 & 1 & 0 & 0 & 0 & 0 & 0 & 0 & 0 & 0 & 0 & 1 & 1 \\
\hline 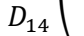 & 11 & 1 & 0 & 0 & 0 & 0 & 0 & 0 & 0 & 0 & 0 & ) & \\
\hline & 1 & 1 & 0 & 1 & 1 & 1 & 1 & 1 & 0 & 0 & 0 & 0 & \\
\hline
\end{tabular}

\subsection{Reachability matrix decomposition}

Decompose the reachability matrix which calculated by MATLAB. The basic hierarchy was alternated by using decomposition matrix. According to the definition of the antecedence set $Q\left(D_{i}\right)$ and reachability set $R\left(D_{i}\right)$ of risk factor, $R\left(D_{i}\right)$ in a multi-level structure of the first stage element $\mathrm{Di}$ must consist of itself and the strong connection element. The most advanced elements Q(Di)just consist by $\mathrm{Di}$, reachability and strong connection elements in next level of $\mathrm{D}_{\mathrm{i}}$. It can be drawn the intersection table (Table 3). Top level unit Di must satisfy $R\left(D_{i}\right)=R\left(D_{i}\right) \cap Q\left(D_{i}\right)$, then look for new top-level elements from the remaining reachability matrix. The basic hierarchical structure (Table 4) of risk factors obtained through continuous iterative.

Table 3 antecedence set Q (Di), reachability set $\mathrm{R}(\mathrm{Di})$ and their intersection set

\begin{tabular}{llll}
\hline $\mathbf{i}$ & $\mathbf{R}\left(\mathbf{D}_{\mathbf{i}}\right)$ & $\mathbf{Q}\left(\mathbf{D}_{\mathbf{i}}\right)$ & $\mathbf{R}\left(\mathbf{D}_{\mathbf{i}}\right) \cap \mathbf{Q}\left(\mathbf{D}_{\mathbf{i}}\right)$ \\
\hline 1 & 1 & $1-15$ & 1 \\
2 & 1,2 & $2,7,11,12$, & 2 \\
& & $13,14,15$ & \\
3 & 1,3 & $3,5,11,12$, & 3 \\
4 & 1,4 & $13,14,15$ & 4 \\
5 & $1,2,3,5$ & 4 & 5 \\
6 & 1,6 & 5,15 & 6 \\
7 & $1,2,7$ & 6,15 & 7 \\
8 & 1,8 & 7,15 & 8 \\
9 & 1,9 & 8,15 & 9 \\
10 & $1,6,10$ & 9,15 & 10 \\
11 & $1,2,3,11,14$ & 10 & 11 \\
12 & $1,2,3,12,14$ & 12 & 12 \\
13 & $1,2,3,13,14$ & 13 & 13 \\
14 & $1,2,3,14$ & 14 & 14 \\
15 & $1,2,3,5,6,7$, & 15 & 15 \\
\hline
\end{tabular}

Table 4 Basic hierarchy of risk factors

\begin{tabular}{ll}
\hline Hierarchy & Risk factor \\
\hline 1 & 1 \\
2 & $2,3,4,6,8,9$ \\
3 & $5,7,10,14$ \\
4 & $11,12,13,15$ \\
\hline
\end{tabular}

\subsection{Construction of ISM}

According to the basic hierarchy which alternated by using decomposition matrix, we construct the structural model (Fig. 4). From the figure we can see that it divided into four levels: The first level is the key issue to be solved - accidents during transport of dangerous chemicals; Second level is direct factor causing traffic accidents which includes driver's driving behavior and vehicle equipment status. Meanwhile internal factors also influence each other, such as vehicle tires problem is always due to overheating of brake; The third and fourth level are indirect factors in transportation accidents, which includes road conditions, weather conditions, 
crashed by other cars, management and other objective factors. These factors cause the accident through affecting the operation of the driver and vehicle equipment.

Although environmental factors are not the direct factor leading to the accident, it can't be ignored. For example, raining can cause road becoming slippery and muddy, resulting in the driver's view is not clear. It may lead to vehicle accidents.
Mismanagement of people or vehicle will increase the probability of occurring fault and accident, such as not comprehensive training of driver and incomplete examination. Enterprise should be prepared to line-selection work to understand the information of destination along the road, weather conditions, terrain features and other information before performing transport tasks, thereby enhancing the safety factor during transport.

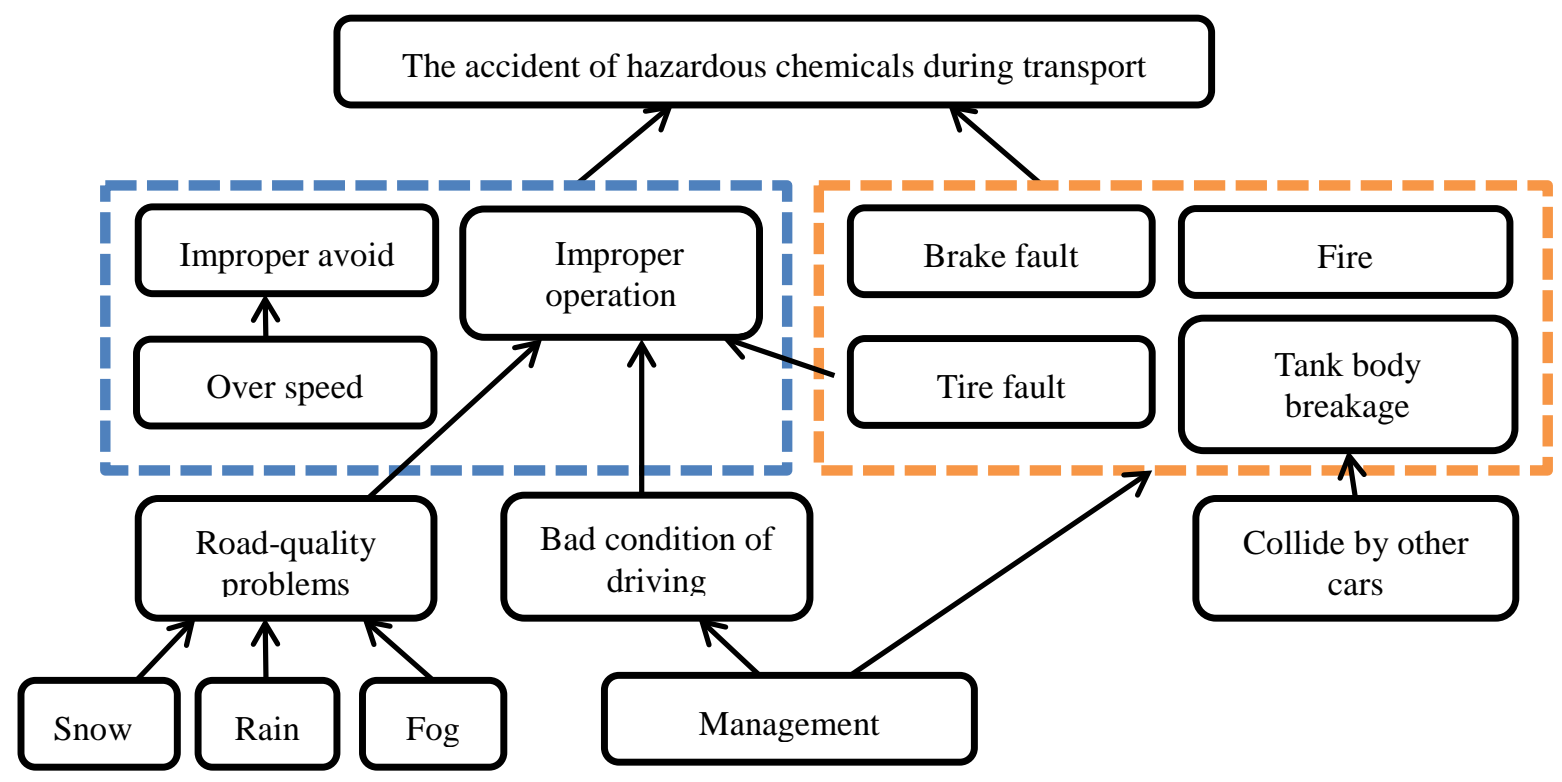

Figure4. The ISM of risk factors in transport of dangerous chemicals

\section{SUMMARY}

The results of the risk analysis evidenced driver behavior and vehicle or equipment factor is the primary factor causing the accident. Improving safety awareness and the level of the driver, strengthening inspection and maintenance of vehicles and equipment can be effective in reducing accidents especially dangerous leak or explosion caused ecological destruction.

Factor which caused accidents during transport do not exist independently but influence each other and are reciprocal causation. To decrease accidents effectively and reduce casualties and property losses, we should control risk factors in all aspects during transport, identifying the sources of danger in process fully and reasonably. What's more, the evaluation of harmful consequences of risk factors must be scientific and standard. Finally, given full consideration to sensitive receptors in the environment during transport is very important.

\section{REFERENCES}

BAI Xiang-en, XIAO Ying-jie, ZHENG Jian, et al. Risk factor analysis on LNG carrier entering or leaving port based on interpretative structural modeling[J]. Journal of Shanghai Maritime University, 2013, 34(4):8-12.

Carlos S. Frequency analysis of hazardous material transportation incidents as a function of distance from origin to incident location[D]. Iowa State University, Ames, Iowa, 2007.

Chemical accident information.[DB/OL]. http://accident.nrcc.com.cn:9090/SafeWeb/index.php

Fabiano,B. , Curro, F. , Palazzi, E.et al. A framework for risk assessment and decision-making strategies in dangerous good transportation[J]. Journal of Hazardous Materials, 2002, 93(1) : 1- 15

SHEN Xiao-yan, LI Xiao-nan, XIE Pe, et al. Statistical analysis on 886 road HAZMAT transportation accidents by the tank truck [J]. Journal of Safety Science and Technology, 2012, 8(11):43-48.

State Administration of Production Safety Supervision and Management. "Catalog of Hazardous chemicals" [EB]. www.chinasafety.gov.cn

WU Zong-zhi, SUN Meng. Statistic analysis and countermeasure study on 200 road transportation accidents of dangerous chemicals [J]. Journal of Safety Science and Technology, 2006, 2(2):3-8 
WU Zong-zhi, ZHANG Sheng-zhu, ZHANG Yue, et al. Statistical analysis of hazardous chemicals accidents occurring in China during 2006- 2010. Journal of Safety Science and Technology, 2011, 7(7) : 5-9

YANG Jun-min , LI Cui-juan , XU Bo. Analysis of Risk Factors in Technology M\&As — Based on Interpretive Structural Model[J].Journal of Shanghai Jiaotong University,2011,45(12):1743-1746. 